\title{
Suction and time effects on the behaviour of a reservoir chalk
}

\author{
G. Priol, V. De Gennaro \& P. Delage \\ Ecole des Ponts (CERMES, Institut Navier), Paris, France \\ F. Collin \& R. Charlier \\ Université de Liège (GEOMAC), Liège, Belgium
}

\begin{abstract}
Oil reservoir rocks contain various immiscible fluids (oil, water and gas) and they are submitted to elevated temperatures in the oilfield. Hence, they exhibit a typical coupled behaviour where multiphysics and coupled Thermo-Hydro-Mechanical aspects are predominant. This paper presents some results from researches carried out within the PASACHALK 2 European funded collaborative research. In this research dedicated to subsidence problems in the North sea Ekofisk oilfield, the behaviour of a reservoir chalk containing two immiscible fluids (an organic non polar fluid and water) is considered within the framework of the mechanics of unsaturated soils (no temperature effects considered). In order to account for the mechanical coupled effects related to the two pore fluids, the oil-water suction was considered as an independent stress variable. The paper presents some experimental results describing the combined effect of suction and time on the isotropic compression behaviour of the chalk. A viscoelastoplastic constitutive model based on one hand on the Barcelona BBM elastoplastic model for unsaturated and on the other hand on Perzyna's approach of viscous behaviour of soils is also presented.
\end{abstract}

\section{INTRODUCTION}

Chalk may contain various immiscible pore fluids in the case of either natural chalks (unsaturated chalk due to low relative humidity) or reservoir rocks (that contain water, oil and gas as pore fluids). Multiphysics couplings take place and make chalk mechanical behaviour more complex. Previous studies have evidenced water weakening with loss of strength (Masson 1973, Bonvallet 1979, Lord et al. 2002). Water weakening is associated with embankment collapse (Clayton 1980, Rat \& Schaeffner 1989), with the long term stability of underground quarry (Bell et al. 1999, De Gennaro et al. 2005) and with weathering damages on natural slopes (Sedki et al. 2002).

Researches into oilfield chalks (Andersen 1995, Schroeder et al. 1996, Risnes et al. 1999, 2000, De Gennaro et al. 2003, 2004) have shown that important physicochemical interactions exist between water, oil and chalk involving collapse and time dependent strain. In order to account for multiphysics couplings in the mechanical behaviour of multiphase chalk, Delage et al. (1996) proposed to use a framework taken from the mechanics of unsaturated soils. Oil-water suction has been used to investigate the transition between the totally saturated states (either by oil or by water). Particular attention has also been paid to the viscous behaviour of multiphase chalk, including loading rate effects (De Gennaro et al. 2003).

In this paper, some experimental data illustrating the time and suction dependent behaviour of multiphase chalk are presented. Data have been obtained from isotropic suction controlled compression tests carried out under various stress rate. A visco-elasto-plastic constitutive law based on the Barcelona Basic Model for unsaturated soils and on Perzyna's approach of viscous behaviour of soil is also presented and applied to the experimental data presented.

\section{MATERIALS AND METHODS}

\subsection{Materials}

Due to the significant cost of field plugs, the tests presented in this paper have been carried out on specimens of an outcrop chalk extracted in a surface quarry near Lixhe (Belgium). This shortcoming may have some important implications in terms of behaviour. Geologically, Lixhe chalk is similar to that of the Ekofisk field (De Gennaro et al. 2003). Lixhe chalk is a pure white chalk with less than $1 \%$ of silica and with an average porosity of about $43 \%$.

The fluid that will be called oil in this study is a non toxic, non aromatic and non polar organic liquid called 


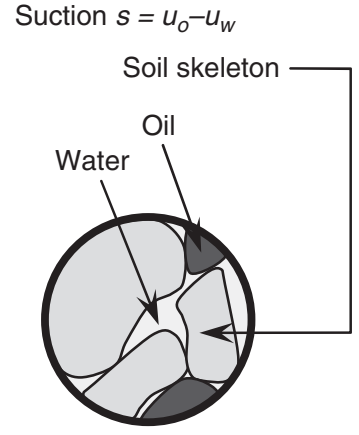

Figure 1. Simplified scheme of oil-water-chalk interactions.

Soltrol 170 (Phillips Petroleum Company). The water solubility of Soltrol 170 is very low and it is not miscible to water. The dynamic viscosity of Soltrol 170 is $\eta_{\text {oil }}=2.028 \mathrm{cP}$ and the density is $\rho_{\text {oil }}=0.78 \mathrm{Mg} / \mathrm{m}^{3}$. Obviously, chalk wettability depends on the fluids used and should obviously be different with Soltrol as compared to crude oil. These changes in wettability obviously affect the oil-water retention properties of chalk.

Figure 1 shows a simplified scheme of oil/water/ chalk interaction based on dominant capillarity effects that could take place in a water wet reservoir chalk. By defining the two pressures $u_{\mathrm{o}}$ and $u_{w}$ as the oil and water pressures respectively, the oil water suction is defined as $s=u_{0}-u_{w}$ as compared to the air/water suction in unsaturated soil that is defined by $s=u_{a}-u_{w}$ where $u_{a}$ is the air pressure.

\subsection{Retention properties}

Figure 2 that gives the changes in water saturation $(x$-axis, linear) obtained under different suctions ( $y$ axis, log scale) presents the results obtained in terms of oil-water retention properties of Lixhe chalk using various techniques. The water drainage curve has been obtained by imposing an increased suction on a specimen initially water saturated. Two different techniques were used. The black dots were obtained using the overpressure techniques in retention cells allowing for the independent control of pressures, based on the use of a high oil entry value porous stone. Black dots refer to the same specimen that has been equilibrated at various increasing suctions up to $s_{o}=0.35 \mathrm{MPa}$.

The continuous line has been deduced from a pore size distribution curve obtained by mercury intrusion. It was obtained by doing a change of the interfacial tension values from the mercury/chalk values $(\theta=$ $141-146^{\circ}$ and $\left.\sigma_{h g-c h k}=480 \cdot 10^{-3} \mathrm{~N} / \mathrm{m}\right)$ to the water/chalk values $\left(\theta=33-73^{\circ}\right.$ and $\sigma_{w-c h k}=44$. $\left.10^{-3} \mathrm{~N} / \mathrm{m}\right)$. A good agreement is observed between the

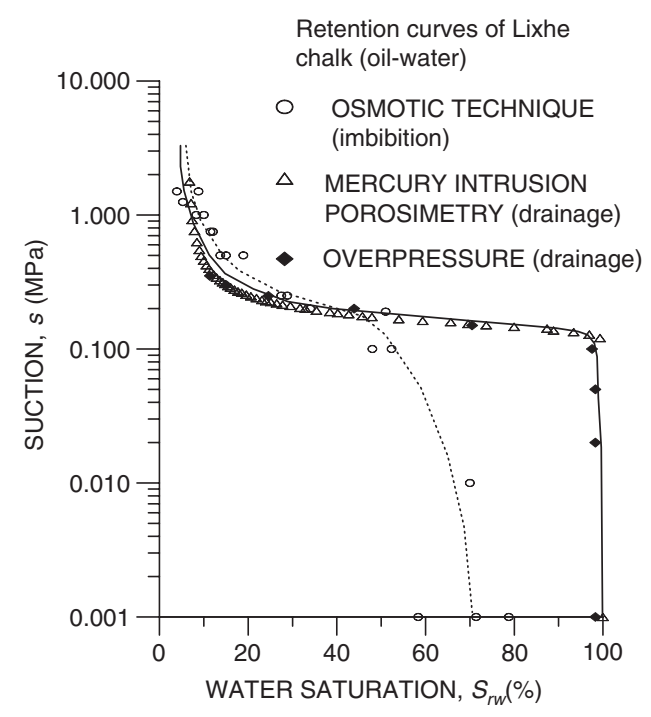

Figure 2. Retention curves of Lixhe chalk (oil/water).

overpressure technique and the porosimetry approach, showing that in the range of suction used with the overpressure technique (up to $0.35 \mathrm{MPa}$ ), most retention phenomena are exclusively governed by capillarity. A residual water degree of saturation $S_{r w}$ of $5 \%$ is observed under a suction of $1.5 \mathrm{MPa}$. Obviously, the significant change in water content observed between $0.11 \mathrm{MPa}$ (oil entry value) and $0.3 \mathrm{MPa}$ corresponds to the emptying of this pore population that corresponds to the inter-grains pores.

The water infiltration curve also presented in Figure 2 was obtained by using the osmotic technique of controlling suction (see De Gennaro et al. 2004). Experimental points were obtained from chalk specimens initially oil saturated. A value of degree of saturation in water $S_{r w}$ comprised between 5 and $10 \%$ is observed at a suction of $1.5 \mathrm{MPa}$. When suction is released $(1.5,1.25,1,0.75,0.5,0.25,0.1$ and $0 \mathrm{MPa})$ water is permitted to progressively infiltrate the specimens by expelling the corresponding volume of oil. Despite the various samples porosities, a satisfactory correspondence is observed between the experimental points obtained.

At a zero suction, the water degree of saturation $S_{r w}$ is comprised between 60 and $80 \%$, which confirms the significant water wettability of Lixhe chalk. The possible oil wettability of some reservoir chalks is due to the coating of the chalk surface by some hydrocarbon components. Obviously, wettability is fundamental property in terms of oil recovery and intense investigation is being carried out on wettability in petroleum engineering (Anderson 1986). 


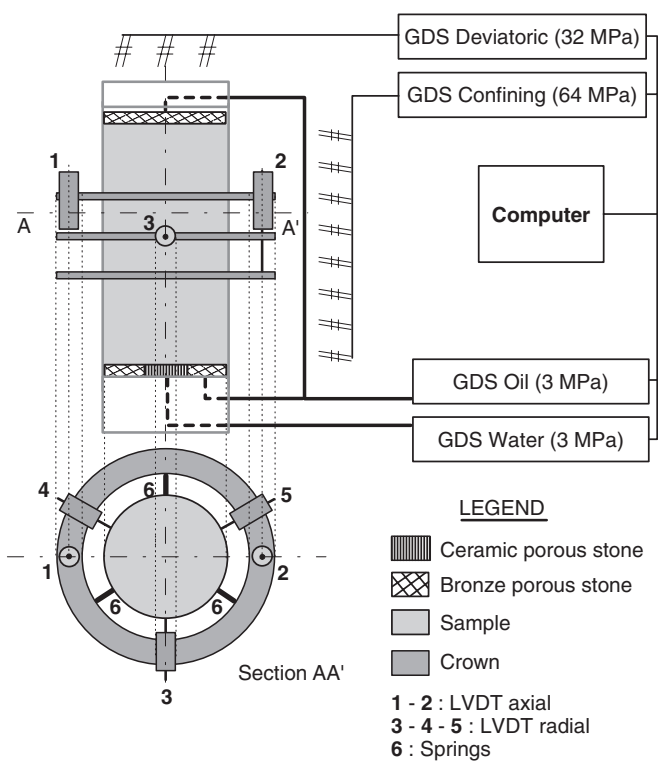

Figure 3. System for local strain measurement.

\subsection{Triaxial testing device and procedure}

Suction controlled tests have been carried out in a high pressure auto-compensated Geodesign triaxial cell on standard specimens $(38 \mathrm{~mm}$ in diameter and $76 \mathrm{~mm}$ in height). The maximum applicable confining pressure and deviatoric stress are respectively $60 \mathrm{MPa}$ and $100 \mathrm{MPa}$. In auto-compensated cells, the application of a confining pressure in the cell is hydraulically compensated and does not change the effort to apply on the piston to shear the specimen. The confining and deviatoric stresses were applied by means of high pressure GDS pressure-volume controllers. In order to impose suction controlled conditions, the overpressure (or axis translation) technique was applied. Oil and water pressures were independently controlled by using two standard GDS pressure-volume controllers $(3 \mathrm{MPa})$. The water pressure was controlled through a small cylinder shaped ceramic high air entry value porous stone placed at the bottom of the specimen. This porous stone ( $1500 \mathrm{kPa}$ air entry value) is impervious to oil in the case of a water/oil couple of fluids.

Local radial and axial strain measurements were carried out by means of a special frame (Figure 3) mounted around the chalk specimen and equipped with 5 LVDTs (Linear Variable Differential Transformers). It consists of three independent rigid rings equally distant one from another, fixed through the central ring around the middle height of the specimen by means of three high stiffness springs oriented at $120^{\circ}$ in the radial direction. The average radial strain is measured via the 3 horizontal LVDTs ( $5 \mathrm{~mm}$ range) oriented at $120^{\circ}$ in the radial direction and mounted on the middle ring.

Starting from an initial oil saturated state, specimens were pre-equilibrated outside the cell using the osmotic technique and inserted in the cell at the desired suction. Subsequent suction control in the cell with the over-pressure technique showed excellent agreement between the two techniques, with small further variations in the degree of saturation of water $(<1 \%)$.

\section{EXPERIMENTAL RESULTS}

As in soils, the rate of application of strain or stress during compression tests run on chalk specimens should be low enough to allow for pore pressure dissipation (Gibson \& Henkel 1954). In unsaturated soils, a constant suction condition also requires low strain rate, as shown by Ho \& Fredlund (1982) and Delage et al. (1987). Observations of literature data shows that axial rates of $1 \mu \mathrm{m} / \mathrm{mn}$ are generally adopted in triaxial testing of unsaturated soils (Delage 2004). Less data are available in chalks in this regard. Havmøller and Foged (1998) considered that axial strain rates of about $0.1 \% /$ h (i.e. $2.7 \times 10^{-7} \mathrm{~s}^{-1}$ ) were slow enough to avoid any excess oil-pressure generation on almost fully oil saturated chalks $\left(S_{r w} \cong 5 \%\right.$ ). Deviator loading rates of $1.6 \times 10^{-4} \mathrm{MPa} \mathrm{s}^{-1}$ have been applied during triaxial tests at constant confining pressure by Homand and Shao (2000) in order to prevent excess pore pressure. However in this case the induced volumetric strain rate was unknown. Two loading rates have been used in this study: a slow one equal to $5.5 \cdot 10^{-5} \mathrm{MPa} / \mathrm{s}$ and a fast one equal to $3.3 \cdot 10^{-3} \mathrm{MPa} / \mathrm{s}$.

The results of some isotropic compression tests are now presented. Beside the three tests carried out on specimens saturated with only one fluid (oil, water and air in the case of the dry sample), and suction controlled tests are also presented. As compared to tests on oil or water saturated specimens, suction controlled tests are aimed at providing an insight into the progressive changes that occur in the oilfield when water progressively replaces oil.

\subsection{Effects of the pore fluids}

The results of the five isotropic compression tests previously presented are presented in Figure 5. In these tests, a fast stress rate of $3.3 \cdot 10^{-3} \mathrm{MPa} / \mathrm{s}$ has been adopted. The figure shows that there is obviously little effect of the pore fluid(s) in the elastic regime whereas differences appear in terms of yield stress and plastic compression. In the plastic regime, the stress-strain curves are correctly ordered as a function of both pore fluid and suction value, as already observed in oedometer compression results by De Gennaro et al. (2004). 


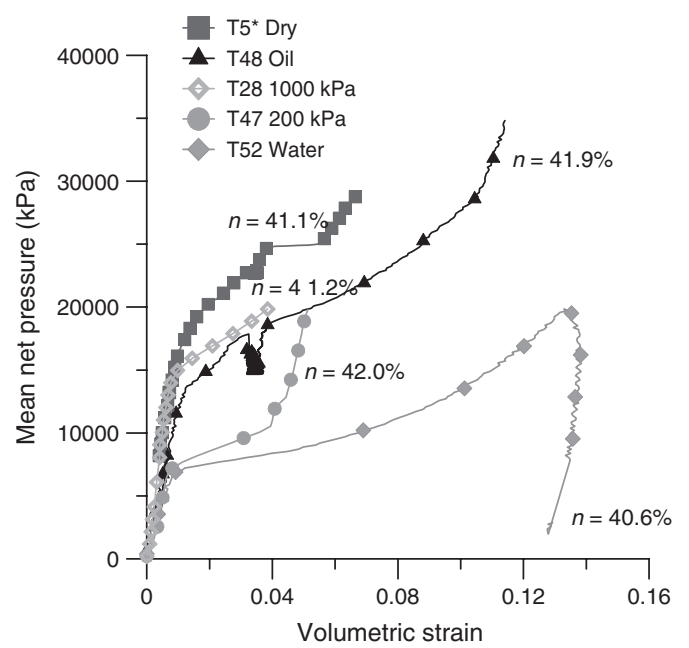

Figure 4. Suction effects on isotropic compressions, fast rate.

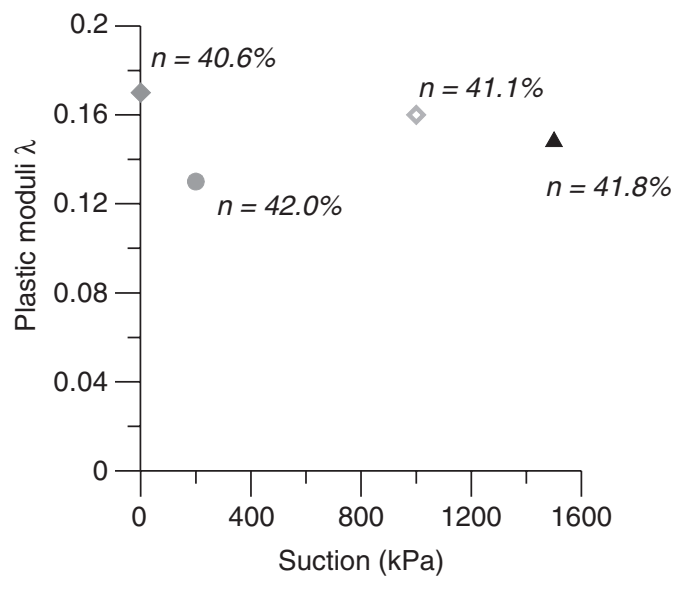

Figure 5. Suction effects on the plastic moduli, fast rate.

However, some effects of the initial porosity on the sample stiffness in the plastic regimes appear to be also considered. The stiffest response obtained with the dry sample $(n=41.1 \%)$ has been commonly observed by various researchers (Masson 1973, Bonvallet 1979). Dry specimen always exhibits the strongest mechanical resistance as compared to specimens containing either water or oil as pore fluid. This appears to be due to some solid inter-grains contacts that are affected when a liquid (either polar on non polar) is introduced in the porosity.

Observation of the compression curve of the oil saturated specimen $(n=41.9 \%)$ shows a response close

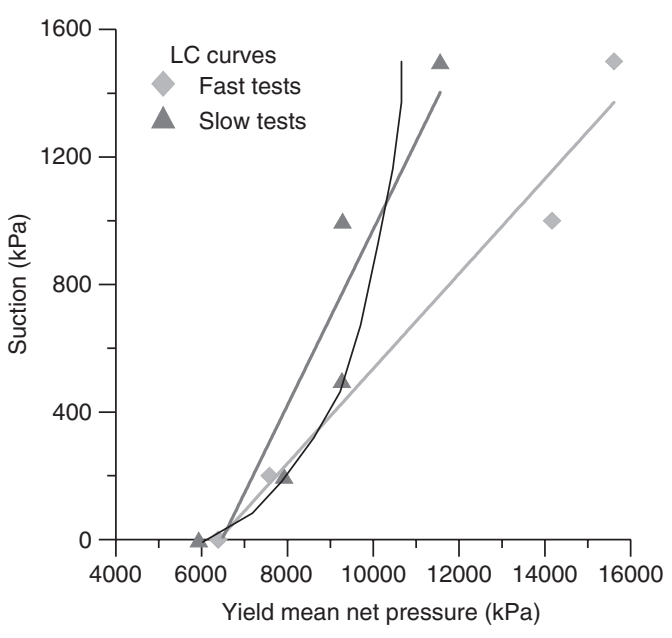

Figure 6. LC curve at two different loading rates.

to that of the specimen under a $1000 \mathrm{kPa}$ suction $(n=$ $41.2 \%$ ). Note that according to the water infiltration curve of Figure 2, there is little water in the specimen under a suction of $1000 \mathrm{kPa}\left(S_{r w}\right.$ close to $\left.5 \%\right)$. However, as shown in the scheme of Figure 1 (where $S_{r w}$ is obviously higher than $5 \%$ ) water as a wetting fluid is located in the smaller pores, close to the inter-grains contact, resulting probably in a significant macroscopic mechanical effect even in small quantities. The correspondence of the two curves is hence related to the combined effect of water weakening and density strengthening.

There is little difference in Figure 5 between the water saturated specimen and that under a $200 \mathrm{kPa}$ suction, although the oil-water retention curve of Figure 2 shows that the water degree of saturation $S_{r w}$ should be close to $50 \%$. Here also, the combined effect due to water and density should play a role, the water saturated sample being denser $(n=40.6 \%)$ than the specimen under a $200 \mathrm{kPa}$ suction $(n=42 \%)$. In the same context, the difference in terms of yield stress appears to be small (6.5 and $7.5 \mathrm{MPa}$ respectively). Some characteristics of the plastic behaviour taken from the curves of Figure 5 are presented in Figure 5 (plastic moduli) and Figure 6 (yield stress). Yield stresses from slow tests are also plotted in Figure 6. In this figure, results obtained from oil saturated specimens are plotted at a suction value of $1.5 \mathrm{MPa}$, according to results of Figure 2.

Figure 5 shows that the effect of suction on the plastic compression modulus is not obvious. This trend is significantly different from what has been observed in unsaturated soils, where higher suction (corresponding to drier soils) involves a significantly stiffer volumetric response. In other words, the plastic compression modulus $\lambda(s)$ defined in the extension of 


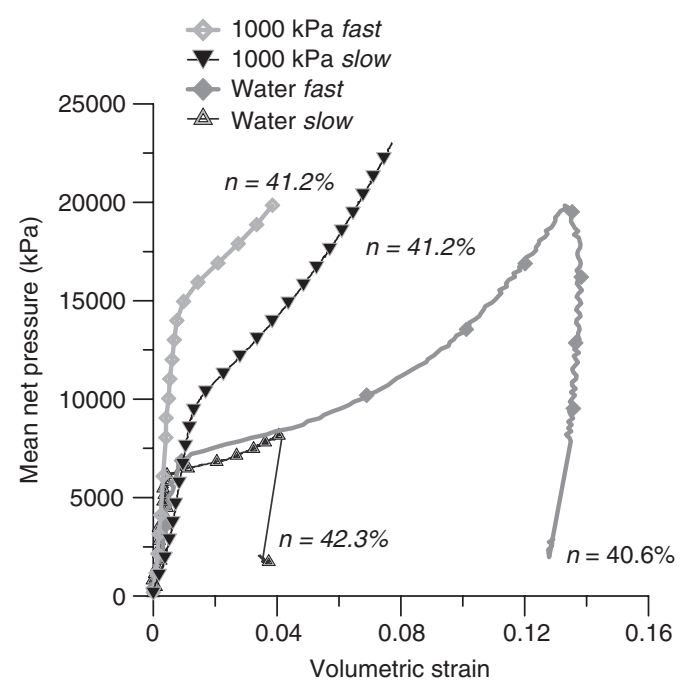

Figure 7. Loading rate effects on isotropic compression tests.

Cam-Clay concepts to unsaturated soils proposed by Alonso et al. (1990) appears to be not suction dependent. Values of $\lambda(s)$ are comprised between 0.12 and 0.17 with no clear trend. Another typical feature of the BBM model is the change in yield stress with respect to suction, called LC curve in a suction versus mean stress diagram. Yield stresses obtained from Figure 5 are reported in Figure 6 and show the shape of the LC curve. As compared to unsaturated where LC curves are curved and delimit a concave elastic zone, LC curves appear to be linear for multiphase chalk. When comparing the LC curves at fast and low rate, the Figure 7 shows a dependency of the LC curve with time that will be discussed in the following section.

\subsection{Loading rate effects}

Figure 7 shows the results of isotropic compression curves carried out at two stress rates, $5.510^{-5} \mathrm{MPa} / \mathrm{s}$ for the slow rate and $3.5 \cdot 10^{-3} \mathrm{MPa} / \mathrm{s}$ for the fast rate, as indicated before. Tests were carried out on a water saturated specimen and on a specimen under a $1000 \mathrm{kPa}$ suction $\left(S_{r w}=5 \%\right)$.

The two specimens under $1000 \mathrm{kPa}$ have same values of porosity (41.2\%) and the comparison between data only accounts for stress rate effect. The difference is notable agreeing standard time dependent behaviours in geomaterials. Increasing the stress rate corresponds to an apparent strengthening and stiffening of the specimen, with increased yield stress $(9$ to $14 \mathrm{MPa}$ ) and plastic modulus (600 to $2500 \mathrm{MPa}$ ). The results of the water saturated specimens are less satisfactory with a slight difference observed between the curves. Two aspects (faster rate and smaller porosity) should have made clearer the distinction between the two curves with higher yield stress reached in the case of the fast test. Combined suction and time effects can be observed in Figure 6. The shape of the LC curves obtained at two stress rate clearly shows that both loading rate and suction when increased have a similar strengthening effect. The diagram also shows that suction strengthening is more significant at a higher suction with an increase of about 1.25 with water saturation and 2.5 with oil saturation. Such results appear to be of interest when considering the combined effect of suction and time on multiphase chalk behaviour.

\section{CONSTITUTIVE MODELLING}

An elasto-visco-plastic constitutive model has been developed to account for suction and time dependent effects in multiphase chalks. Suction effects have been introduced based on an adaptation of the BBM model (Alonso et al., 1990). This model in which a cap has been introduced has been called the Pasachalk model (Charlier et al. 2002, Collin et al. 2002). Then the model has been extended using the framework of Perzyna's viscoplasticity (1964) with the elastoplastic BBM model. In such a way, the yield surfaces of BBM become potential surfaces for the description of viscous effects, with an amplitude depending on distance between the stress point and the potential surface. Previous experiments performed on chalk specimens have evidenced the occurrence of two plastic mechanisms: the pore collapse for high mean stresses (contracting behaviour) and the frictional failure for low mean stresses.

\subsection{Presentation of the constitutive model}

Following the additivity postulate, the strain rate is composed of both a mechanical part (superscript $m$ ) and a suction part (superscript $s$ ). Each contribution is partitioned in an elastic (superscript $e$ ) and a plastic component (superscript $p$ ):

$$
\dot{\varepsilon}_{i j}=\dot{\varepsilon}_{i j}^{m, e}+\dot{\varepsilon}_{i j}^{s, e}+\dot{\varepsilon}_{i j}^{m, p}+\dot{\varepsilon}_{i j}^{s, p}
$$

For the plastic part, a general framework of nonassociated plasticity is adopted in order to limit dilatancy. Elastic and plastic strains related to suction changes are defined following BBM expressions. Irreversible strains are induced when the suction becomes higher than a suction level $s_{o}$, they are as follows:

$$
\dot{\varepsilon}_{i j}^{s, e}=\frac{\kappa_{s}}{(1+e)} \frac{\dot{s}}{\left(s+p_{a t}\right)} \delta_{i j}=h_{i j}^{e} \dot{s}
$$


$\dot{\varepsilon}_{i j}^{s, p}=\frac{\lambda_{s}-\kappa_{s}}{(1+e)} \frac{\dot{s}}{\left(s+p_{a t}\right)} \delta_{i j}=h_{i j}^{p} \dot{s}$

where $e$ is the void ratio, $p_{a t}$ is the atmospheric pressure, $\kappa_{s}$ and $\lambda_{s}$ are elastic and plastic coefficients. The Modified Cam-Clay yield surface is defined by the following expression:

$f_{1} \equiv I I_{\hat{\sigma}}^{2}+m^{2}\left(I_{\sigma}+\frac{3 c}{\tan \phi_{C}}\right)\left(I_{\sigma}-3 p_{0}\right)=0$

where $c$ is the cohesion, $\phi_{C}$ is the friction angle in compression path, $p_{0}$ is the preconsolidation pressure that defines the size of the yield surface and $m$ is a coefficient introduced to take into account the effect of the third stress invariant. Note that in multiphase chalks $p_{0}$ represents a yield stress rather than a preconsolidation pressure. This nomenclature will be preferred hereinafter. The coefficient $m$ is defined by:

$m=a(1+b \sin 3 \beta)^{n}$

where the parameters $a, b$ and $n$ must verify some convexity conditions (Van Eekelen, 1980). Assuming an associated plastic flow, the yield stress $p_{0}$ is related to the volumetric plastic strain $d \varepsilon_{v}^{p}$ according to the kinematic equation:

$d p_{0}=\frac{1+e}{\lambda-\kappa} p_{0} d \varepsilon_{v}^{p}$

where $\lambda$ and $\kappa$ are respectively the plastic and elastic compression coefficients. Expression (6) allows accounting for both hardening and softening according to the sign of the volumetric plastic strain. However, in the cap model, the softening zone will not be considered. On the other hand, it should be noted that the irreversible volumetric strain includes the coupled effect of mechanical and suction changes.

\subsection{Suction effect on the yield surface}

The yield stress $p_{0}$ and the material stiffness increase with suction. This feature is described by the $\mathrm{LC}$ curve in the BBM model, as follows:

$p_{0}(s)=p_{c}\left(\frac{p_{0}^{*}}{p_{c}}\right)^{\frac{\lambda(0)-\kappa}{\lambda(s)-\kappa}}$

with

$\lambda(s)=\lambda(0)\left[(1-r) \exp \left(-\beta^{\prime} s\right)+r\right]$

where $p_{0}^{*}$ is the yield stress for $s=0, p_{c}$ is a reference pressure, $\lambda(0)$ is the compression coefficient at zero suction, $\lambda(\mathrm{s})$ is the compression coefficient at suction

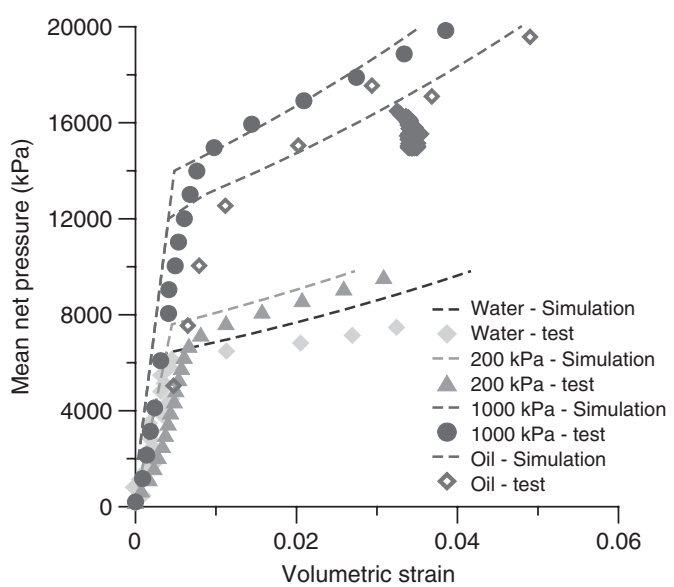

Figure 8. Suction effects modeling.

$s, r$ is a parameter representing the maximum stiffness of the chalk, and $\beta^{\prime}$ is a parameter controlling the stiffness increase with suction increase. As far as no suction effects have been observed on the plastic flow rule, the LC curve has been considered as linear, in accordance with the experimental results of Figure 6.

Also, experiments on chalk show that friction angle is independent of the saturating fluid. Suction changes may create irreversible strains. In the BBM model, this is modelled thanks a yield surface called the SI "Suction Increase" curve. When suction becomes higher than a suction level $s_{0}$, plastic strains are created. This yield criterion is introduced as follows: $f_{4} \equiv s-s_{0}=0$.

\subsection{Elastoviscoplastic model}

Time dependent effects in chalk are well known and they have been experimentally observed previously in terms of strain rate dependency. A time dependent behaviour modelling of fully saturated chalk is now introduced based on the elastoviscoplastic approach proposed by Perzyna (1964). The major advantage of this approach is the possibility to formulate the elastoviscoplastic model moving directly from the general theoretical structure of an elastoplastic model. The irreversible strain being normal to a potential $g$ can be written as:

$\underline{\dot{\varepsilon}}^{v p}=\gamma\langle\phi(f)\rangle \frac{\partial g}{\partial \underline{\sigma}}$

This formulation is close to an elastoplastic formulation but it is not based on the consistency condition. The amount of strain rate is described with respect to a reference surface $f$, similar to the yield surface. Then, two irreversible mechanisms are introduced: the pore 


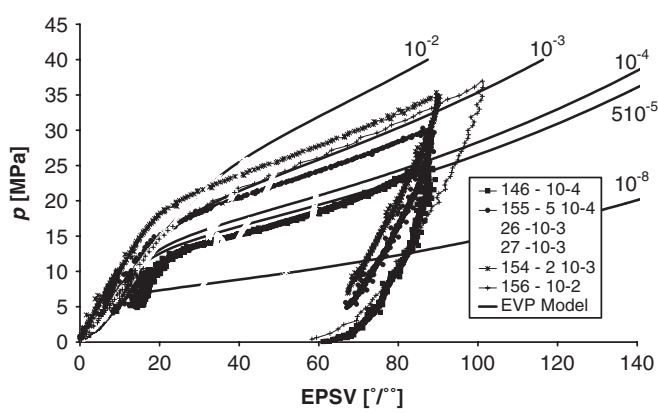

Figure 9. Stress-strain-time modelling.

collapse and the friction failure. Pore collapse is based on the following equations:

$\left\langle\phi_{c}\left(f_{c}\right)\right\rangle=\left(\frac{f_{c}}{3 p_{0}^{2}}\right)^{\alpha_{c}}$

and (Shao et al., 1993):

$\gamma_{c}=\omega\left(\frac{I_{\sigma}}{p_{a}}\right)^{t}$

where the reference surface $f_{c}$ is similar to the yield surface of the Pasachalk model (4). Function $f_{c}$ may be analysed as an overstress, i.e. a measurement of the amount of the stress state located outside the yield or reference surface. Moreover, the overstress is only positive when the stress state is outside the yield reference surface; then, considering the McAulay brackets used in equations (9) and (10), the higher the overstress, the higher the irreversible strain rate.

The hardening rule defined by the plastic hardening rule of Eq. (6) is adopted. A similar approach has been adopted for friction failure, with no major difficulties. Figure 9 shows a comparison between experimental results and the viscoplastic model predictions. Oil saturated samples were loaded at different stress rate ranging between $10^{-4} \mathrm{MPa} / \mathrm{s}$ and $10^{-2} \mathrm{MPa} / \mathrm{s}$.

\section{CONCLUSION}

Reservoir chalk is a multiphase material, which contains various immiscible fluids (oil, water, occasionally gas). Within the Pasachalk 2 European funded collaborative research, multiphysics couplings in the Lixhe chalk has been intensively investigated and the influence of suction and time effects was observed on the chalk isotropic behaviour. The yield stress is an increasing function of these two parameters. A constitutive model has been proposed combining the BBM for the suction effects and the Perzyna's approach for the viscous terms. The model predictions are in agreement with the experimental data obtained during the project.

\section{ACKNOWLEDGEMENTS}

The authors would like to express grateful appreciation for the financial support offered by the EC commission for the PASACHALK 2 research program (ENK62000-00089) in collaboration with TOTAL Norge.

\section{REFERENCES}

Alonso, E.E., Gens, A. \& Josa, A. 1990. A constitutive model for partially saturated soils. Géotechnique, 40(3): 405430.

Andersen, M.A. 1995. Petroleum Research in North Sea Chalk. Public. Rogaland Research - Stavanger, Norway.

Anderson, W.G. 1986. Wettability Literature Survey Part 1-5. Journal of Petroleum Technology 38-39.

Bell, F.G., Culshaw, M.G. \& Cripps, J.C. 1999. A review of selected engineering geological characteristics of English chalk, Engineering geology, 54, pp. 237-269.

Bonvallet, J. 1979. Une classification géotechnique des craies du nord utilisée pour l'étude de stabilité des carrières souterraines. Revue Française de Géotechnique, 8: 5-14.

Charlier, R., Collin, F., Schroeder, Ch., Illing, P., Delage, P., Cui, Y.-J. \& De Gennaro, V. 2002. Constitutive modelling of chalk - application to waterflooding. Proc. 2nd Biot Conference, Grenoble, France.

Collin, F., Cui, Y.-J., Schroeder, Ch. \& Charlier, R. 2002. Mechanical behaviour of Lixhe chalk partly saturated by oil and water : experiment and modeling. Int. J. for Num. Anal. Meth. in Geomechanics 26, 897-924.

Clayton, C.R.I. 1980. The collapse of compacted chalk fill. In Proc. Colloque Int. Sur le compactage, Paris, vol. 1, pp. 119-124.

De Gennaro, V., Delage, P., Cui, Y.-J., Schroeder, Ch., Collin, F. 2003. Time-dependent behaviour of oil reservoir chalk: a multiphase approach. Soils and Foundations, $\mathbf{4 3}$ $\mathrm{n}^{\circ}$ 4, pp. 131-148.

De Gennaro, V., Delage, P., Priol, G., Collin, F. \& Cui, Y.J. 2004. On the collapse behaviour of oil reservoir chalk. Géotechnique, 54(6), pp. 415-420.

De Gennaro, V., Delage, P., Priol, G., Sorgi, C. \& Collin, F. 2005. Multiphase viscous behaviour of two different outcrop chalks, XIème IACMAG, Turin.

Delage, P., Suraj De Silva, G.P.R. \& De Laure, E. 1987. Un nouvel appareil triaxial pour les sols non saturés. Proc. 9th Eur. Conf. Of Soil Mechanics, Dublin, pp. 26-28.

Delage, P., Schroeder, Ch. \& Cui, Y.J. 1996. Subsidence and capillary effects in chalk. Proc. Eurock'96, Turin, pp. 1291-1298.

Delage, P. 2004. Experimental unsaturated soil mechanics. Proceedings of the 3nd International Conference on Unsaturated Soils, UNSAT'2002, Vol. 3, 973-996, Recife, Brasil, Balkema.

Gibson, R.E. \& Henkel, D.J. 1954. Influence of the duration on tests a constant rate of strain on measured drained strength, Géotechnique 4(1), pp. 6-15.

Havmoller, O. \& Foged, N. 1998. Reviews of rock mechanics data for chalk. Joint Chalk. Research IV.

Ho, D.Y. \& Fredlund, D.G. 1982. Strain rates for unsaturated soil shear strain testing. Proc. 7th South East Asia conf. soil mech. and found. eng. Hong-Kong, pp. 787-803. 
Homand, S. \& Shao, J.F. 2000. Mechanical behaviour of a porous chalk and effect of saturating fluid. Int. J. of Mechanics of cohesive-frictional materials 5, pp. 583-606.

Lord, J.A., Clayton, C.R.I. \& Mortimore, R.N. 2002. Engineering in chalk, CIRIA, Londres, p.332.

Masson, N.M. 1973. Pétrophysique de la craie, Bulletin des laboratoires des ponts et chaussées, spécial V, pp. 23-48.

Perzyna, P. 1964. The constitutive equations for rate sensitive plastic materials, Quart. Appl. Mech., 20: 321-332.

Rat, M. \& Schaeffner, M. 1989. Classification of chalks and conditions of use in embankments. Proc. Chalk Symposium Brighton, pp. 425-428.

Risnes, R. \& Flaageng, O. 1999. Mechanical properties of chalk with emphasis on chalk-fluid interactions and micromechanical aspects. Oil \& Gas science and technology. Rev IFP, 54, n6, pp. 751-758.
Risnes, R. \& Nygaard, V. 2000. Chalk behaviour in the elastic region. Proc. 6th Chalk symposium JCR V, Brighton.

Schroeder, Ch. \& Shao, J.F. 1996. Plastic deformation and capillary effects in chalks. Proc. 5th North Sea Chalk Symp., Reims.

Sedki, S., Boulemia, C., Colbeaux, J.-P., Van Laethem, F. Henry, E. \& Carlier, E. 2002. The instability analysis of chalk cliffs of the Blanc Nez cape. Proc. 15th ASCE Eng. Mech. Conf., New York.

Shao, J.-F., Bédériat, M. \& Schroeder, C. 1993. A viscoplastic theory for soft rock behaviour and application. Geotechnical engineering for hard soils soft rocks. pp. 795-802.

Van Eekelen, HAM. 1980. Isotropic yield surfaces in three dimensions for use in soil mechanics. International Journal for Numerical and Analytical Methods in Geomechanics, 4, pp. 98-101. 